\title{
Sarcoidosis after Adjustable Silicone Gastric Banding - a Report of Two Cases in Germany
}

\author{
Christine Stroh ${ }^{a, d} \quad$ Joachim Böttger $^{b}$ Frank Meyer $^{c}$ Hans Lippert ${ }^{c, d}$ Thomas Manger ${ }^{a, d}$ \\ ${ }^{\text {a }}$ Department of General, Abdominal and Paediatric Surgery, Municipal Hospital, Gera, \\ ${ }^{\mathrm{b}}$ Department of Surgery, Helios Hospital, Bad Saarow, \\ ${ }^{c}$ Department of Surgery, University Hospital, Magdeburg, \\ ${ }^{\mathrm{d}}$ Institute of Quality Assurance in Surgery at the Otto-von-Guericke University Magdeburg, Germany
}

\section{Key Words}

Obesity surgery · Gastric banding · Sarcoidosis

\section{Summary}

We report 2 patients who developed sarcoidosis after the implantation of adjustable silicone gastric banding (GB) in Germany. Before implantation, no pulmonary diseases were evident in the medical history of either patient. The 1st patient suffered sarcoidosis 12 months after GB. He has been treated at a hospital specialising in pulmonary diseases. Because of the treatment with corticoids, the patient has regained weight after the initial weight reduction. The 2nd patient developed signs of pulmonary infection on the 7th postoperative day (after GB). Pulmonary sarcoidosis was diagnosed 4 months later after consultation with a pulmonologist.

\section{Introduction}

Approximately 1.7 billion people worldwide are overweight or obese [1]. Morbid obesity is associated with numerous comorbidities, such as diabetes, hypertension, cardiac diseases, sleep apnoea syndrome, and degenerative skeletal diseases. Every year, about 2.5 million obese people die from such comorbidities.

According to meta-analysis data worldwide, gastric banding (GB) is performed in $24.1 \%$ of bariatric procedures [2]. In Germany, according to the data of the prospective study [3] on 'Quality Assurance in Bariatric Surgery in Germany', GB was the most frequently performed bariatric operation (40.1\%) from January 1, 2005, to December 31, 2007.

Reports of the development of pulmonary or scar sarcoidosis after GB have yet to be published.

\section{KARGER}

Fax +497614520714

Information@Karger.de

www.karger.com (c) 2009 S. Karger GmbH, Freiburg

Accessible online at:

www.karger.com/ofa

\section{Case Report}

We report on 2 patients, 1 male and 1 female, who developed pulmonary sarcoidosis after implantation of GB. Neither patient had any medical history of pulmonary diseases or severe pulmonary complications.

Case 1

A 29-year-old man underwent adjustable silicone GB to treat morbid obesity in July 1997; his preoperative BMI was $62.65 \mathrm{~kg} / \mathrm{m}^{2}$. In cases of overweight patients without any sufficient pneumoperitoneum, conversion from a laparoscopic to an open approach is necessary. A Lap-Band ${ }^{\circledR}$ (INAMED Health, Santa Barbara, CA, USA) was used. The patient developed postoperative deep venous thrombosis and was treated with low-molecular-weight heparin. During the 1st postoperative year, excess weight loss was $53.6 \%$, and his BMI dropped down to $42.3 \mathrm{~kg} / \mathrm{m}^{2}$. However, the patient showed an enlargement of the mediastinum in X-rays. His general practitioner sent the patient to a hospital specialised in pulmonary diseases where pulmonary sarcoidosis was diagnosed. Treatment with corticoids in high doses was started, and, at this time, the patient began to regain weight. His BMI increased to $54 \mathrm{~kg} / \mathrm{m}^{2}$ in 2 years and then to $57.5 \mathrm{~kg} / \mathrm{m}^{2} 3$ years after GB. Because of the pulmonary alteration and the corticosteroid and immunosuppressive treatment of the patient, a removal of the band and/or a conversion to a malabsorptive procedure was not undertaken. In the past few years, his BMI ranged from 47 to $60 \mathrm{~kg} / \mathrm{m}^{2}$. From a surgical point of view, we did not see any connection between the implantation of the GB and development of sarcoidosis until the 2nd case occurred in Germany in 2007 and was reported to us.

\section{Case 2}

A 52-year-old female patient with a preoperative BMI of $42 \mathrm{~kg} / \mathrm{m}^{2}$ underwent GB in September 2007. In her medical history, the patient suffered from many kinds of allergies, especially to latex and penicillin and other drugs. Because of her coronary heart disease, the patient received an endovascular stent in September 2004. Due to her morbid obesity, the implantation of a gastric band was suggested. The operation, in which a Swedish adjustable gastric band (SAGB; Obtech Medical Sàrl, Le Locle, Switzerland) was implanted, was uneventful. The patient was discharged at the 2 nd postoperative day, but she suffered a fever on the 7th postoperative day (fig. 1). Outpatient treatment with different antibiotics was begun, but treatment with antibiotics was ineffectual. Additionally, the patient did not show any signs of band infection on the CT scan. 2 months after the primary operation, a pleuritis was diagnosed, but a chest X-ray 


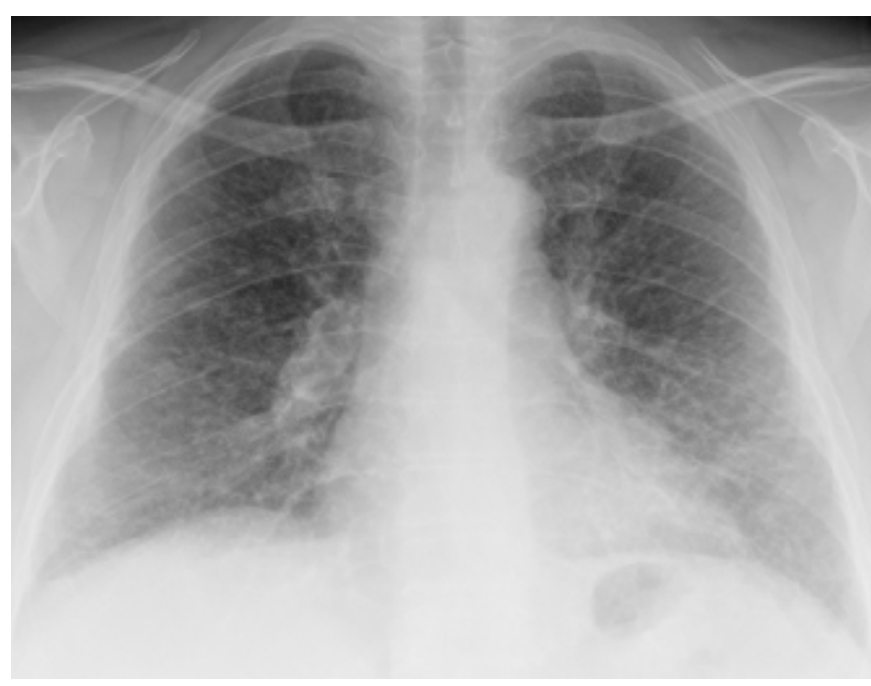

Fig. 1. X-ray on the 7th postoperative day after SAGB.

showed no signs of pulmonary infiltration. In January 2008, a pulmonary infiltration with radiological signs of tuberculosis was diagnosed by a chest X-ray (fig. 2). Bronchoscopy did not show any pathological findings. A thoracoscopy was performed to exclude tuberculosis by histological examination, and sarcoidosis was diagnosed during this examination. After an extensive review of the literature, focusing on reports of sarcoidosis after silicone breast implants, the band was removed 4 months after implantation. Retrospectively, the radiological signs of sarcoidosis were observable on the chest X-ray on the 7th postoperative day.

\section{Discussion}

Sarcoidosis is a multisystem granulomatous disease of unknown etiology, presenting most commonly with bilateral hilar lymphadenopathy, pulmonary infiltration or cutaneous manifestations, or eye lesions. The diagnosis is established when radiological findings are supported by histological evidence of widespread noncaseating epitheloid cell granuloma.

The first theory regarding the cause of sarcoidosis was proposed in 1960 and stated that silicate materials undergo chemical 'weathering' in the tissue, thus forming colloidal silica, which may produce an epitheloid response [4].

The 2nd theory, proposed by Rank [5], hypothesised that the reaction to silica arises either through delayed-type hypersensitivity or as a non-allergic foreign body reaction to a colloidal substance. The response occurs over time and only in susceptible individuals.

The 1st report that connected silica and sarcoidosis was published in 1963 [6]. After the injection of silica into a scar, epithelioid granulomas were induced. The findings of this study indicated that colloidal and allergic granulomas can be distinguished when specific histological criteria are applied. The evidence from the authors was that the formation of epithelioid granulomas, namely sarcoidosis, is based on the

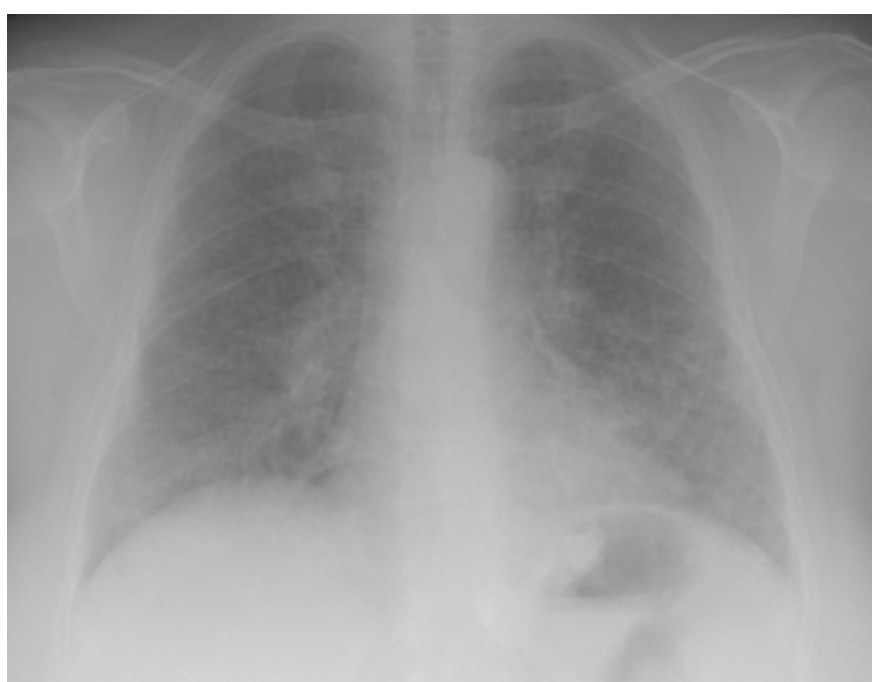

Fig. 2. X-ray before thoracoscopy exhibiting radiological signs of tuberculosis or sarcoidosis.

mechanism of hypersensitivity. In 1974, Mohri [7] discussed the connection of silicates and sarcoidosis as well.

The pathological picture of silica granuloma formation, as described by Lever and Schaumberg-Lever [8], is an allergic foreign body reaction with a typically tuberculoid pattern consisting of epithelioid cells.

Another report described a higher incidence of sarcoidosis in workers exposed to diatomaceous earth and cristobalite. The exposure to silica has been suggested to have an effect on the immune system, which has drawn attention to the possible association of silica exposure and autoimmune disease [9].

In the literature, there are only a few available reports of sarcoidosis after implantation of silicone prosthetic material. Most of the reports describe sarcoidosis after breast prosthesis implantation. Besides sarcoidosis, the development of Löfgren syndrome is also described in the literature as an autoimmune reaction [10]. In these cases, the removal of the foreign material, along with immunosuppressive treatment, is suggested. Nevertheless, there is no evidence of the induction of sarcoidosis by silicone devices and material. That is why complications like sarcoidosis, autoimmune reaction, and allergies should be reported to reach evidence on possible reactions of the silicone material. The risk of sarcoidosis after GB has not been previously described in the literature.

For all GB patients with a medical history of latex allergies, we performed dermatological and allergy diagnostics in our hospital prior to GB. However, it needs to be determined if an allergy to latex is a contraindication of GB. We would suggest sleeve gastrectomy (SG) as the bariatric procedure of choice in patients with a history of allergic reactions to multiple allergens.

Some authors suggested performing GB on patients who suffered from sarcoidosis prior to band implantation [11]. In 
this case, the patient was also treated with immunosuppressive substances.

According to our experience, we would not suggest GB for patients who are on immunosuppressive treatments. We would prefer to perform SG as a single-step procedure in these patients. The risk of complications due to the foreign material of the banding and long-term complications due to band migration should be avoided.

\section{Conclusion}

In light of the reported delayed-type hypersensitivity reactions to silicone implants, we should be aware of sarcoidosis as a short- and long-term complication after the implanta- tion of silicon materials, such as a gastric band. Furthermore, the risk of inducing gastric cancer also needs to be considered. In the literature, evidence for an association between silica exposure and oesophageal and gastric cancer is described [12].

We would suggest that patients with a medical history of allergies, especially to latex, should undergo allergy diagnostics, and patients with these allergies should decline GB. These cases show that sarcoidosis should be a contraindication for GB.

\section{Disclosure}

The authors declared no conflict of interest.

\section{References}

1 Deitel M: Overweight and obesity worldwide now estimated to involve 1.7 billion people. Obes Surg 2003;13:329-330.

2 Buchwald H, Avidor Y, Braunwald E, Jensen MD, Pories W, Fahrbach K, Schoelles K: Bariatric surgery. A systematic review and meta-analysis. JAMA 2004;292:1724-1737.

3 Stroh C, Birk D, Flade-Kuthe R, Frenken M Herbig B, Höhne S, Köhler H, Lange V, Ludwig K, Matkowitz R, Meyer G, Meyer F, Pick P, Horbach T, Krause S, Schäfer L, Schlensak M, Shang E, Sonnenberg T, Susewind M, Voigt H, Weiner R, Wolff S, Lippert H, Wolf AM, Schmidt U, Manger T; Bariatric Surgery Working Group: A nationwide survey on bariatric surgery in Germany - results 2005-2007. Obes Surg 2009;19:105-112.
4 Shelly WB, Hurley HJ: The pathogenesis of silica granulomas in man: a non-allergic colloidal phenomenon. J Invest Dermatol 1960;34:107-123.

5 Rank BK, Hicks JD, Lovie M: Pseudotuberculoma granulosum silicoticum. Br J Plast Surg 1972;25:4248.

6 Epstein WL, Skahen R, Krasnobrod H: The organized epithelioid cell granuloma: differentiation of allergic (zirconium) from colloidal (silica) types. Am J Pathol 1963;43:391-405.

7 Mohri N: Anisotrope Substanzen in Lymphknoten bei Sarkoidose. Virchows Arch A Path Anat Histol 1974;362:259-264.

8 Lever WF, Schaumberg-Lever G: Histopathology of the Skin. Philadelphia, PA, Lippincott, 1984, pp 221-224.
9 Rafnsson V, Ingimarsson O, Hjalmarsson I, Gunnarsdottir $\mathrm{H}$ : Association between exposure to crystalline silica and the risk of sarcoidosis. Occup Environ Med 1998;55:657-660

10 Barzo P, Tamasi L: Löfgren syndrome after silicone breast prosthesis implantation (in Hungarian). Orv Hetil 1998;139:2323-2326.

11 Labeck B, Nehoda H, Kähler C, Freund M, Aigner F, Weiss HG: Adjustable gastric banding in a patient with sarcoidosis. Surg Endosc 2001;15:1361.

12 WHO: Cristalline silica, quartz. Concise International Chemical Assessment Document (CICAD) No. 24. Geneva, WHO, 2000. 